\title{
The impact of poor working memory skills on a Grade 2 learner's written and oral literacy performance
}

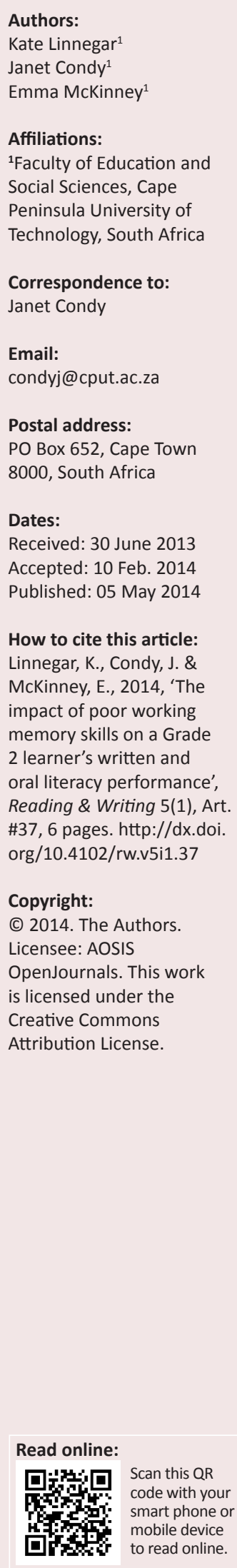

This research examines the effects of poor working memory skills on a Grade 2 learner. Mediated learning is the theoretical framework that underpins this research project as the focus is on developing cognitive functions, particularly focusing on the working memory of a learner. An independent case study was conducted on one learner, using a qualitative research approach. Interviews and observations were conducted and inductively analysed. The learner followed a six-week intervention programme which was dynamically informed by recent literature as well as observations, interviews and a psychologist's report. The findings indicated that the learner's working memory, with particular reference to processing and storage, was challenged. The large demands of the classroom environment led to memory failure and he was prone to making errors. He experienced slow progress in his reading abilities, was unable to retain words and his reading was inconsistent. To alleviate some of his working memory demands, activities and instructions were broken down into smaller components to minimise his memory load, thus avoiding working memory related failures.

\section{Introduction}

This research aims to examine the effects of poor working memory skills on a Grade 2 learner and explores how these difficulties impact on his performance in literacy. Working memory is a mental workspace that can be used flexibly to support everyday cognitive activities that need both processing and storage, such as comprehension, reasoning and learning (Alloway 2006:134). In a classroom situation, learners with poor working memory skills tend to forget lengthy instructions, miss out letters or words in sentences and fail to cope with simultaneous storage and processing demands (ibid:137).

This research explores the theoretical framework applied to working memory according to Haywood (1993). Working memory will be defined and discussed, including the different components involved in working memory. An intervention programme focusing on supporting one learner experiencing working memory deficit in a literacy classroom environment will be discussed.

\section{Theoretical framework}

Haywood (1993:27) explains that mediated learning experiences (MLE) are essential for the adequate cognitive development of learners. Through MLE the learner learns how to solve problems. With the help of the mediator, attempts are made at extending the learner's thinking process so that they can transcend the experience and learning into new everyday life situations. Basic cognitive functions need to be acquired; these can be achieved through learning (ibid:30). MLE assists learners in developing these cognitive functions by developing an understanding of the meaning of the world. This entails helping them to understand that events, objects and people have meaning beyond themselves and that the world has a predictable structure and understanding (ibid:27). He believes that this structure helps learners to know what to do in future situations. According to Haywood (ibid:27), the immediate goal of MLE is for learners to acquire the important cognitive functions that trigger the ability to learn effectively across different fields. If some aspects of cognitive development have not been stimulated through MLE, it is possible to mediate these aspects at a later stage through carefully constructed teaching.

With regard to the case study, the learner had deficits with his working memory. This study used MLE and constructed teaching to assist the learner in utilising his working memory and to limit his impulsive responses, with the hope of improving the quality of his engagement with tasks. The purpose of this research was to explore what effects the implementation of working memory skills will have on a learner during classroom learning activities. Through the literature reviewed on working memory, this research will also ascertain what effects working memory skills have on the learner's performance in literacy. 


\section{What is working memory?}

According to Alloway (2006:134) working memory is the 'system responsible for temporarily storing and manipulating information'. Alloway (ibid:134) states that working memory is a mental workspace that can be used flexibly to support everyday cognitive activities that need both processing and storage, such as comprehension, reasoning and learning. However, the capacity of a learner's working memory is limited (ibid:134). If the learner is storing a surplus of information in a cognitive activity or the process demands on their working memory are too great, it could lead to 'catastrophic loss of information from this temporary memory system' (ibid:134).

Riding, Grimley, Dahraei and Banner (2003:149) cited in Baddeley and Hitch (1974) developed a working memory model with three components: the central executive, the phonological loop and the visuospatial sketch pad. All three components have a limited capacity for information they are able to store and manipulate. The central executive component functions as the control system and is responsible for coordinating the input and output of information and for sending the information to the sub-systems (ibid:149). This component deals with cognitively demanding tasks such as mental arithmetic and problem-solving (ibid:149). Riding et al. discuss the function of the phonological loop, which is the part of the working memory that deals with verbal information over short periods of time as well as written material. Lastly, the visuospatial sketch pad processes and stores visual and spatial information. According to Baddeley (2003:837), the working memory model makes two predictions: firstly, if two tasks make use of the same component of working memory, they cannot be performed successfully together. Secondly, if two tasks make use of different components of working memory, it should be possible to perform them together.

In general classroom learning situations, children with poor working memory skills can forget lengthy instructions, miss out letters or words in sentences and fail to cope with simultaneous processing and storage demands (Alloway 2006:137). A reason for these failures is that the simultaneous storage and processing demands of the learning activity are beyond the working memory capacities of these learners. Alloway (ibid:137) suggests that in isolation the learner should be able to store information without difficulty. However, the added processing demands of the classroom environment increase the working memory demands and therefore lead to memory failure. A learner with a weak working memory capacity is therefore limited in their ability to perform in different classroom learning activities (ibid:137).

According to Gathercole and Pickering (2000:177), there are links between a learner's capability to store and manipulate information over brief periods and their achievements in different learning outcomes such as vocabulary, language comprehension, reading and mathematics. Alloway, Gathercole and Elliot (2010:632) agree with this idea as they claim that there is now substantial evidence that working memory is linked to key learning outcomes in literacy and numeracy. Daneman and Carpenter (in Riding et al. 2003) hypothesise that:

working memory is used to represent the strategies and skills used in a complex mental task such as reading, with the remaining capacity used to store the resulting products of the reading comprehension. (p. 149)

They suggest that whilst information is being processed and the products of this processing are being stored, the two components of processing and storage compete for the limited capacity of working memory available, resulting in the learner losing some of the stored information.

Alloway (2006:134) states that working memory is important for working out complex mental activities because the learner has to keep in mind some information whilst processing other materials at the same time. Alloway (ibid:134) emphasises that carrying out mental activities like this are effortful and error-prone as any minor distraction, such as an unrelated thought or an interruption by someone else, will most likely result in complete loss of the stored information and so a failed attempt at the activity. Therefore, a learner with a limited working memory capacity will have difficulties in trying to work out mental activities.

This review of the literature and theory surrounding working memory has examined the use of MLE programmes in supporting learners' cognitive development. Working memory has been defined and discussed with reference to the different components involved in working memory. The challenges facing learners with working memory difficulties have been highlighted with the subject area of literacy being given as an example.

\section{Research method Research design}

An independent case study was conducted on one learner who experienced difficulties with his working memory. According to Shank and Brown (2007:64), researchers need to take their time observing, probing and gathering different types of information to get an insightful look at the learner. A qualitative research method was used. Qualitative research is 'a type of empirical research that focuses on the study of meaning' (ibid:239). This research project was conducted within a Grade 2 classroom environment in a private mainstream primary school in a high socio-economic urban area of Cape Town, South Africa.

Purposive sampling was used. According to Bogdan and Knopp Biklen (2007:73), certain case studies are chosen because they are thought to facilitate the development of the evolving theory. One learner was intentionally chosen. The learner was a six-year-old boy who was referred to an educational psychologist as he was exhibiting difficulties in task completion and understanding. The psychologist's report stated that this learner experienced difficulties with his working memory. He had the potential to achieve a high 
standard of work and giving him strategies to help him utilise his working memory more effectively would assist him in achieving better results. The learner attended a Grade 2 class in a private mainstream school. The learning support teacher at this school and the learner's previous Grade 1 teacher were purposively selected to gather a deeper knowledge of how this learner's working memory impacted on his academic abilities.

\section{Data collection procedure}

Multiple methods, namely observations, interviews and document analysis, were used to collect the data as literature has suggested that the use of multi-methods will ensure that the study has been investigated using different sources of information, thus giving the data variety (Henning, Van Rensburg \& Smit 2004:6). After using interviews, observations and documents as methods of data collection, the information was triangulated to interpret the results. In the following paragraphs the advantages and disadvantages of interviews, observations and document analysis will be briefly discussed.

The researcher decided to use semi-structured interviews with the Grade 1 teacher and the learning support teacher as she realised she needed to gather information, opinions and insights from different perspectives (Shank \& Brown 2007:63). In preparation for the semi-structured interviews the researcher prepared a set of questions, further indepth probing questions, as well as a column to record any interesting body language that may have occurred during the interview (Koshy 2010:87). One of the advantages of conducting an interview is that interview transcripts provide powerful evidence when you are presenting your data and making conclusions' (Koshy 2010:88). Through these interviews, the researcher was able to obtain another perspective on the learner and was able to identify common themes in each teacher's experience with the learner. These interviews took place in August 2012, before the implementation of the intervention programme.

Observation plays an important role in gathering data. Observation is a natural process as we are always observing people and occurrences and, based on these observations, we make judgments (Koshy 2010:92). As a participatory observer, the researcher observed the learner, within the classroom setting whilst he was completing his work. Shank and Brown (2007:62) feel that observation is critical and simple. They state that 'while there are many observational protocols, the basic idea is simple - go somewhere and pay attention'. The researcher found that an advantage of observing the learner is that she got an opportunity to make a note of his reactions, such as frustration and disinterest, which are also important aspects of data collection (Koshy 2010:94). However, if the learner is aware of the observation it may affect his behaviour which might negatively impact the result of the observation.

Since the case study's performance was inconsistent and varied from day to day or during different times of the day, the researcher observed the learner in the morning and after break over a four-week period. The learner experienced the greatest challenges in literacy, so the researcher observed his performance in various activities in this learning area, namely reading, comprehension, grammar and creative writing. A set of guidelines, established by the researcher, were followed to help guide the observations. These guidelines gave the researcher criteria for the observations. The focus of the observations was on the way the learner was able to answer questions verbally and in written form. During some of the observations, the learner was observed in a micro-group setting with four learners in the group and other observations were conducted individually with him at his desk.

From the observations, after taking continuous notes on the pre-planned observation schedule, the researcher gathered data that gave an indication of how the learner was able to use his working memory in literacy activities.

According to Koshy (2010:90) documents can offer significant evidence for the research study and are useful for building the whole picture of the particular case study chosen. The learner's educational assessment was used to gather background information. A registered psychologist's report indicated that the learner had a weak working memory. However, this information was limited and did not contribute to developing the intervention programme.

\section{Data analysis}

Henning et al. (2004:101) describe data analysis as taking apart words, sentences and paragraphs in order to make sense of, interpret and theorise the data. In the course of the inductive data analysis, the researcher transcribed the interviews and referred to the observations, dividing the information into smaller and more meaningful sections. The interviews were transcribed verbatim and compared to the observation schedules. After reading all this data many times common themes began to emerge. These themes were coded and categorised and refined into three conceptual similarities: concentration, reading and reading comprehension and writing.

\section{Trustworthiness}

When considering the validity of data in action research, researchers need to consider the accuracy of what is collected and used as evidence. Koshy (2010:98) posits that 'we have to be aware that the conclusions are based on the quality of what we gather as data'. Interpretations of the same observations can vary between different people and this can affect the validity of the data presented. By interviewing the learner's previous teacher and the learning support teacher, who both had a chance to observe him, the researcher was able to discuss the observations with them and determine common themes, thereby making sure that the data was valid, reliable and accurate.

The researcher used triangulation to gather interpretations of a teaching situation from three different points of view 
(Koshy 2010:98). According to Rule and John (2011:109), 'triangulation refers to the process of using multiple sources and methods to support provisions or findings generated in a case study'. Through using triangulation the data was shared and checked; it was gathered from the interviews, observations and document analysis, and confirmed with all involved.

Rule and John (2011:111) state that conducting research ethically will improve the quality of the research and contribute to its trustworthiness. Written permission from the principal of the school to conduct the research study was obtained, as well as written consent from the learners' parents. These responses were kept anonymous and confidential. It was important for the researcher to respect and protect the learner's and his family's rights to be fully informed of the researchers' intentions and for them to decide whether they would like to take part in the study.

\section{Intervention programme}

Underpinning the intervention programme was the theory of mediated learning. Haywood (1993:28) believes that every child, no matter how 'intelligent', must acquire the basic cognitive functions in order to think logically, perceive the world in structured, orderly and reasonable ways, know how to learn and apply his intelligence to new learning and problem-solving situations without further need of mediation.

The focus of the intervention programme was to give the learner strategies to help him utilise his working memory more effectively in the literacy lessons. Gathercole and Alloway (2007:13) recommend that the teacher monitor the learner's classroom learning activities and modify them in order to ensure that he is working within his working memory capacity rather than being overloaded. It was important to ensure that the learner could remember what he was doing. Many learners with low working memory simply forget what they have to do next (Alloway 2006:138). In cases where the learner had forgotten crucial information or instructions for a literacy task, the instructions were frequently repeated to him and he was encouraged to request information when he needed it (Gathercole \& Alloway 2007:15). It was ensured that instructions were as brief and simple as possible. What was included in the intervention programme was to always ensure that the learner had not forgotten crucial information by getting him to repeat the instruction. To alleviate some of his working memory demands, activities, such as reading comprehensions and instructions for starting a literacy activity, were broken down into smaller components to minimise his memory load, thus avoiding working memory related failures. The overall amount of material that had to be stored was reduced (Gathercole \& Alloway 2007:16) by shortening the sentences that needed to be written or the number of instructions that needed to be remembered. Multistep tasks were separated into separate independent tasks, supported by visual cues. The learner was encouraged to use different tools that support memory, such as useful spelling charts displayed in the classroom, dictionaries and picture cards. These tools assisted him in reducing the processing demands and storage load of the tasks. Learners with low working memory skills have difficulty in writing sentences (Gathercole \& Alloway 2007); in this study the learner was urged to write shorter sentences with simple vocabulary, using common words instead of more unusual ones. These interventions took place during all literacy lessons, including grammar, creative writing and reading comprehension.

\section{Findings}

From the analysis of the data collected from observations of the learner and interviews with his previous teacher and the learning support teacher, the following themes became evident:

- concentration

- reading and reading comprehension

- writing.

\section{Concentration}

On observing the learner in the literacy classroom, the researcher found that he frequently forgot lengthy instructions as he often failed to cope with simultaneous processing and storage demands. The demands of the learning activities were beyond his working memory capacities. Alloway (2006:137) explains that in isolation the learner should be able to store information without difficulty. However, the added processing demands of the classroom environment seemed to increase the working memory demands on the learner, which led to memory failure. When carrying out mental activities, the learner was prone to errors. Minor distractions, such as an unrelated thought that sprung into his mind or an interruption by someone else, sometimes resulted in him losing the information he had stored. Thus, he experienced a failed attempt at his activity and needed to start over again. The researcher recalled from observing the learner that 'he gets distracted easily by other thoughts and ideas and by his peers around him'. His previous teacher said that 'he would often get distracted while working on paper, so I found that having him one-on-one with me would often work best for him'.

\section{Reading and reading comprehension}

After interviewing the learner's previous teacher and the school's learning support teacher, as well as observing the learner in the classroom whilst he was working, it was evident that he struggled in the areas of simultaneous memory processing and storage. According to the learning support teacher, this was a challenge he had presented with throughout his schooling thus far. Whilst observing the learner during reading comprehension activities the researcher was able to see that he was able to recall an answer from the text verbally but struggled to write this answer in his workbook. He tended to leave out words and his sentences were often disjointed. During her interview, the learning support teacher, who had an extensive background 
knowledge of the learner, discussed his reading progress; she said that:

'after learning his first set of words, she [his previous teacher] noticed that he showed very slow progress. ... He wasn't retaining the words as much as he should, he wasn't progressing as fast as he should and it [his reading] was very inconsistent'.

In a reading lesson during observation, the learner frequently did not remember what he had read and was unable to answer questions about the story. He had to go back and read over the text another time. It was observed that 'he can recall simple points from the text but had to read over the text again to find more complex answers'.

Gathercole and Pickering (2000:177) believe that there are links between a learner's capability to store and manipulate information over brief periods of time and their achievements in different learning outcomes such as vocabulary, reading and comprehension, thus echoing the learning support teacher's sentiments. This was evident from the class observations of the learner. When doing comprehensions, the learner would need to ask for support in answering questions and he would need to read over the story a few times. During the observations it was noticed that:

'he had to read over the story quite a few times to find the answers, he got quite anxious and needed a lot of support and prompting from [the teacher]'.

\section{Writing}

After examining the learner's literacy workbook it was noted that when writing sentences and stories, the learner repeatedly missed out letters or words in his sentences. The research has shown that when utilising one's working memory to recall an answer from a text or a sentence you want to write, you are not only focusing on the formation of the sentence and letters, but also on the spelling of the words (Gathercole \& Alloway 2007). This made writing a very slow and lengthy process for the learner. His previous teacher recalled:

'When it came to writing the answers down in his book, he wouldn't always get through as many answers as he wanted.... His sentences weren't often full sentences, which in Year 1 was what he was supposed to be completing. ... He would leave out words or he would just get distracted and not complete the task or sentence he was busy with'.

The learner also struggled to copy work off the whiteboard in the classroom, something also noted by his previous teacher. He would often lose his place and forget what he was supposed to be doing.

\section{Discussion}

Alloway (2006:138) states that on many occasions learners with low working memory simply forget what they have to do next. This was noticed in observing the learner. In cases where the learner had forgotten important information, this information was frequently repeated and the learner was encouraged to ask for information when he needed it, assisting him to stay on task (Gathercole \& Alloway 2007:15). It was ensured that instructions were as brief and simple as possible. One of the best ways to guarantee that the learner had not forgotten important information was to get him to repeat the instructions. To alleviate some of his working memory demands, activities and instructions were broken down into smaller components to minimise his memory load, thus avoiding working memory related failures. The learner was able to focus for a longer period of time and remember what he was supposed to do next. One of the significant findings was that the overall amount of material that had to be stored was reduced by shortening the sentences that he had to write and the number of instructions that he needed to remember (Gathercole \& Alloway 2007:16). This alleviated the working memory demands on the learner and he was able to focus better on his work. Multi-step tasks were broken into separate independent tasks, which were supported by visual cues. The learner was encouraged to use different tools to support his memory, namely spelling charts displayed in the classroom, his dictionary and picture cards. This assisted him to reduce the processing demands and storage load of the tasks. Using visual aids assisted the learner in remembering where he was and what he was doing as trying to think of how to spell a word would not distract him.

Learners with low working memory skills have difficulty in writing sentences (Gathercole \& Alloway 2007). When writing, the learner wrote shorter sentences with simple vocabulary, using common words instead of more complex ones. This helped his sentences to flow and not to be disjointed. After a while, the learner was able to start selfcorrecting his work, by reading over his sentences to see if he had left any words out and checking to see if they made sense.

\section{Conclusion}

This research has explored what working memory is and the challenges learners with weak working memory face in a literacy classroom. The areas that were focused on were concentration, reading, comprehension and writing. This was a qualitative study of one learner and the findings cannot be generalised. Moreover, it is possible that the growth observed only occurred due to the intervention programme. Even if there were limited benefits to this learner, it seems a slight improvement that allowed this learner an opportunity to attempt to reach his potential. Perhaps further improvements could have been achieved if the intervention programme had been run over a longer period of time.

\section{Acknowledgements Competing interests}

The authors declare that they have no financial or personal relationships that may have inappropriately influenced them in writing this article.

\section{Authors' contributions}

K.L. (Cape Peninsula University of Technology) was a parttime Honours student and conducted this research in her 
own class. J.C. (Cape Peninsula University of Technology) and E.M. (Cape Peninsula University of Technology) were lecturers on this programme and provided support and feedback to K.L. throughout this project.

\section{References}

Alloway, T., 2006, 'How does working memory work in the classroom?', Educational Research and Reviews 1(4), 134-139.

Alloway, T., Gathercole, S. \& Elliot, J., 2010, 'Examining the link between working memory behaviour and academic attainment in children with $A D H D$ Developmental Medicine \& Child Neurology 52(7), 632-636. http://dx.doi. org/10.1111/j.1469-8749.2009.03603.x, PMid:20163434

Baddeley, A., 2003, 'Working memory: Looking back and looking forward', Nature Reviews: Neuroscience 4, 829-839. http://dx.doi.org/10.1038/nrn1201, PMid: Reviews: Neur
14523382

Bogdan, R.C. \& Knopp Biklen, S., 2007, Qualitative research for education, Pearson, Boston.
Gathercole, S. \& Alloway, T., 2007, Understanding working memory, Harcourt Assessment, London. PMCid:PMC2662929

Gathercole, S. \& Pickering, S., 2000, 'Working memory deficits in children with low achievements in the national curriculum at 7 years of age', British Journal of Educational Psychology 70,177-195. http://dx.doi.org/10.1348/000709900158047, PMid:10900777

Haywood, H.C., 1993, 'A meditational teaching style', International Journal of Cognitive Education and Mediated Learning 3(1), 27-38.

Henning, E., Van Rensburg, W. \& Smit, B., 2004, Finding your way in qualitative research, Van Schaik, Pretoria.

Koshy, V., 2010, Action research for improving educational practice, Sage, Los Angeles.

Riding, R., Grimley, M., Dahraei, H. \& Banner, G., 2003, 'Cognitive style, working memory and learning behaviour and attainment in school subjects', British Journal of Educational Psychology 73, 149-162. http://dx.doi.org/10.1348/00070990360626912, PMid: 12828810

Rule, P. \& John, V., 2011, Your guide to case study research, Van Schaik, Pretoria.

Shank, G. \& Brown, L., 2007, Exploring educational research literacy, Routledge, New York. PMCid:PMC2206633 